\title{
Energy efficient of the residential buildings based climatic condition using experimental design: a case study in malaysia
}

\author{
Seyed Mojib Zahraee ${ }^{1}$, Morteza Khalaji Assadi1,*, Sajjad Bayat ${ }^{2}$, and Shokoufeh Bakhoda ${ }^{1}$ \\ ${ }^{1}$ Department of Mechanical Engineering, Universiti Teknologi PETRONAS, Bandar Seri Iskandar \\ 32610, Perak, Malaysia \\ ${ }^{2}$ Faculty of Mechanical Engineering, Department of Materials, Manufacturing \& Industrial \\ Engineering, Universiti Teknologi Malaysia, 81310 Skudai, Johor, Malaysia
}

\begin{abstract}
In recent years, energy consumption has become a critical issue in the developed and developing countries. Residential buildings are one of the most users of energy in the construction sector that use the highest share of energy. This paper aims at evaluating the effect of four factors that are temperature, humidity, airflow and pressure on the cooling load in the residential buildings. To achieve this goal, statistical experimental design is used to determine the optimum setting of factors that result in optimum energy usage. Simulation software and energy analysis is used to simulate a two-storey building in Malaysia as the case of study. Final results showed that the temperature, humidity and interaction between them have the most significant effect on the energy cooling load. Moreover, to obtain the minimum value of cooling load the temperature and humidity should be equal to $\mathrm{A}=20$ Celsius degree and $\mathrm{B}=60 \%$ respectively. In addition, the other two insignificant factors, airflow and pressure should be placed at the high level which are equal to $\mathrm{C}=3$ cubic meters per hour, and $\mathrm{D}=6$ Pascal $(\mathrm{P})$ respectively.
\end{abstract}

\section{Introduction}

Energy optimization plays an important role in the new world. There is a global concern due to a probable lack of energy in the near future as well as some environmental effects like global warming [1]. Energy is becoming more and more costly and greenhouse gas emission is the disastrous effect of global warming that threat the whole human life [1]. One of the most cost-effective measures to minimize of carbon dioxide emission is to improve the energy efficiency of buildings [2]. Hence, energy efficiency is a key factor that should has been considered as an effective solution [1]. Among the widest range of energy consumers, residential buildings consume the largest amount of energy most of which is consumed by air conditioning systems in tropical countries [3]. In tropical regions with naturally hot and humid weather, a high amount of energy has to be consumed to provide a tolerable environment. In Malaysia it is claimed that air conditioning and refrigerators consumed nearly $70 \%$ of the electricity in buildings [3]. In this paper one residential building in Malaysia was simulated using Revit Architecture as a case study. The statistical method,

*Corresponding author : morteza.assadi@utp.edu.my 
Design of Experiments (DOE) was applied to assess the effect of four climatic factors that are temperature, humidity, airflow and pressure on the cooling load and energy saving.

\section{Literature review}

There are some investigations about the energy efficiency assessment in the residential buildings that are discussed here briefly. One case study in in the humid and hot climate in Saudi Arabia used Visual DOE4 software to assess the energy consumption of a five storey office building [4]. The results indicated that increasing the insulation thickness does not have any considerable impact on energy efficiency. Another study in Singapore applied thermal analysis software (TAS) to investigate the effect of some microclimatic criteria on minimization of the heat in terms of passive climate control in residential buildings that are ventilated naturally [5]. In another study in Saudi Arabia, the impact of three factor on energy saving was investigated. The results claimed that these factors can enhance the thermal comfort and energy usage [6]. Recently, some investigations were done by using combined computer simulation and statistical analysis for enhancing the performance of construction process such as concrete pouring process and energy consumption in buildings $[7,8]$. In one study, Experimental design (DOE) approach was implemented to find the best combination of some selected factors in a two-storey building which located in Malaysia. Final result indicated that changing ceilings and ceiling materials play a significant role to decrease energy consumption [3]. Additionally, in another study, statistical Taguchi method was proposed to find the optimum value of the main parameters of buildings that are window, ceiling, and wall along with the effect of uncontrollable factors such as humidity, temperature, and air flow in residential buildings[9]. In another research, building simulation and DOE were combined to evaluate the effect of main climate factors on energy saving and cooling load. Final result showed that the temperature and humidity have the most significant effect on the energy saving [10]. Therefore, this paper aims at evaluating the effect of four factors that are temperature, humidity, airflow and pressure on the cooling load in the residential buildings. To achieve this goal, building simulation and Design of Experiments (DOE) is applied to find an optimum setting of factors by doing the sensitivity analysis.

\section{Materials and method}

\subsection{Simulation model and experimental design}

In this study, a two-story building separated into 2 uniform apartments (each level 1 unit) was selected Malaysia. Total building area is $676 \mathrm{~m}^{2}$. The house is separated into eleven zones with separate thermal properties for each level. Revit Architecture software is one of the most useful dynamic simulation tools that is used to simulate the building. In order to simulate, the CAD drawings are imported to Revit Architecture and simulated there by particular parametric design principles. The specifications were re-assigned to Ecotect software and a final sketch-up was imported to Energy Plus software.

DOE is a statistical technique first suggested by R.A. Fisher in the 1920's. DOE assess the effect of main factors and interaction between them on the responses variable [11]. In order to implement DOE, the following steps are followed. The steps are: 1 . Selection of the factors and their levels, 2. choosing a response variable, 3. Determination of experimental design 4. Running the experiments 5. Analysis of results 6 . Conclusion and recommendations. 


\subsection{Choosing factors and response variable}

As mentioned earlier, four climatic factors were chosen to examine their effects on the cooling load in the selected case. Table 1 shows the variation range or level of factors is indicated that each factor has a high $(+)$ and low (-) level. Cooling load was considered as a response variable. Due to small number of factors, full factorial design $\left(2^{n}\right)$ is used. In factorial design, all possible combinations of factors are considered in an experiment, which is replicated two times in order to decrease the error. In addition, three center points are considered to examine the curvature of experiment.

Table 1. Factors and levels

\begin{tabular}{|c|c|c|c|}
\hline Factor Name & Low Level (-) & Center (0) & High Level (+) \\
\hline $\mathrm{A}=$ Temperature (Celsius) & 20 & 23 & 26 \\
\hline $\mathrm{B}=$ Humidity (Percent) & 60 & 70 & 80 \\
\hline $\mathrm{C}=$ Air Flow ( $\left.\mathrm{M}^{3} / \mathrm{hr}\right)$ & 1 & 2 & 3 \\
\hline $\mathrm{D}=$ Pressure (Pascal) & 2 & 4 & 6 \\
\hline
\end{tabular}

\section{Result and discussion}

\subsection{Performing simulation experiment}

Table 2 shows the result of 35 experiments that is run using the simulation software.

Table 2. Result of simulation experiment

\begin{tabular}{|c|c|c|c|c|c|c|}
\hline \multirow{2}{*}{$\begin{array}{c}\text { Run } \\
\text { Order }\end{array}$} & \multirow[b]{2}{*}{ Temperature } & \multirow[b]{2}{*}{ Humidity } & \multirow[b]{2}{*}{ Air flow } & \multirow[b]{2}{*}{ Pressure } & \multicolumn{2}{|c|}{ Response (Cooling load) } \\
\hline & & & & & $\begin{array}{c}\text { Replication } \\
1\end{array}$ & $\begin{array}{c}\text { Replication } \\
2\end{array}$ \\
\hline 1 & 20 & 60 & 3 & 2 & 199400 & 199350 \\
\hline 2 & 26 & 60 & 1 & 6 & 225120 & 224140 \\
\hline 3 & 26 & 80 & 3 & 2 & 260160 & 289400 \\
\hline 4 & 20 & 80 & 3 & 6 & 219450 & 225300 \\
\hline 5 & 26 & 80 & 1 & 2 & 255508 & 278570 \\
\hline 6 & 26 & 60 & 3 & 2 & 215600 & 210470 \\
\hline 7 & 20 & 80 & 1 & 6 & 213050 & 235780 \\
\hline 8 & 20 & 60 & 1 & 6 & 199150 & 199400 \\
\hline 9 & 20 & 80 & 3 & 2 & 214179 & 236100 \\
\hline 10 & 26 & 60 & 1 & 2 & 214370 & 199160 \\
\hline 11 & 20 & 60 & 1 & 2 & 198370 & 198240 \\
\hline 12 & 26 & 80 & 3 & 6 & 287150 & 278358 \\
\hline 13 & 20 & 80 & 1 & 2 & 220346 & 250558 \\
\hline 14 & 20 & 60 & 3 & 6 & 199200 & 198240 \\
\hline 15 & 26 & 80 & 1 & 6 & 276900 & 287220 \\
\hline 16 & 26 & 60 & 3 & 6 & 223470 & 235480 \\
\hline 17 & 23 & 70 & 2 & 4 & \begin{tabular}{|l|l|}
297800 & 22 \\
\end{tabular} & \begin{tabular}{l|l}
70 & 297670 \\
\end{tabular} \\
\hline
\end{tabular}

\subsection{Determination of significant factors}

In this study, Minitab software was used. P-value is a significant parameter that is usually used to identify the statistically significant factors, because it has influenced the final 
responses. It should be noted that, whenever P-values are less than 0.05 , they should be considered as a significant. In contrast, when P-values are more than 0.05 , they should be assumed as an insignificant factor [11]. Table 3 shows main effects of A (Temperature), B (Humidity) and two-way interaction (AB) are significant factors.

The normal probability plot of effects shows that the significant factors are far from the line [11]. Figure 1 shows main effects of A (Temperature), B (Humidity) and two-way interaction (AB) are significant factors. Pareto chart is also used to compare the sequence of the statistical significance of the both main and interaction effects from highest to lowest effects. The factors that exceed the reverence line are considered to be significant with the confident level of $95 \%$ (Figure 2).

Table 3. ANOVA table for cooling load

\begin{tabular}{|c|c|c|c|c|c|}
\hline Source & $\begin{array}{l}\text { Degree of } \\
\text { Freedom }\end{array}$ & Seq SS & Adj MS & $\mathbf{F}$ & P-Value \\
\hline A & 1 & 10734531395 & 10734531395 & 24.05 & 0.00 \\
\hline $\mathrm{B}$ & 1 & 15644197391 & 15644197391 & 35.04 & 0.00 \\
\hline $\mathrm{C}$ & 1 & 1238345 & 1238345 & 0.00 & 0.959 \\
\hline $\mathrm{D}$ & 1 & 11451702 & 11451702 & 0.03 & 0.875 \\
\hline $\mathrm{AB}$ & 1 & 2758629212 & 2758629212 & 6.18 & 0.023 \\
\hline $\mathrm{AC}$ & 1 & 662889563 & 662889563 & 1.48 & 0.239 \\
\hline $\mathrm{AD}$ & 1 & 952693988 & 952693988 & 2.13 & 0.161 \\
\hline $\mathrm{BC}$ & 1 & 365614601 & 365614601 & 0.82 & 0.377 \\
\hline $\mathrm{BD}$ & 1 & 28658128 & 28658128 & 0.06 & 0.803 \\
\hline $\mathrm{CD}$ & 1 & 107600783 & 107600783 & 0.24 & 0.629 \\
\hline $\mathrm{ABC}$ & 1 & 17560220 & 17560220 & 0.04 & 0.845 \\
\hline $\mathrm{ABD}$ & 1 & 107982534 & 107982534 & 0.24 & 0.629 \\
\hline ACD & 1 & 303386186 & 303386186 & 0.68 & 0.421 \\
\hline BCD & 1 & 15988099 & 15988099 & 0.04 & 0.852 \\
\hline $\mathrm{ABCD}$ & 1 & 169321403 & 169321403 & 0.38 & 0.546 \\
\hline Curvature & 1 & 5578800419 & 5578800419 & 12.5 & 0.2 \\
\hline $\begin{array}{c}\text { Residual } \\
\text { error }\end{array}$ & 18 & 8035451463 & 446413970 & & \\
\hline Total & 34 & 45495905430 & & & \\
\hline
\end{tabular}

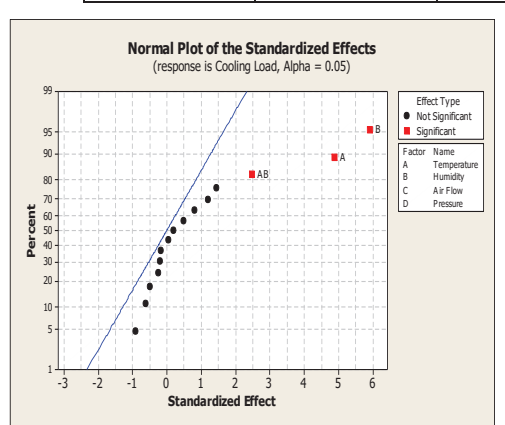

Fig. 1. Normal probability plot

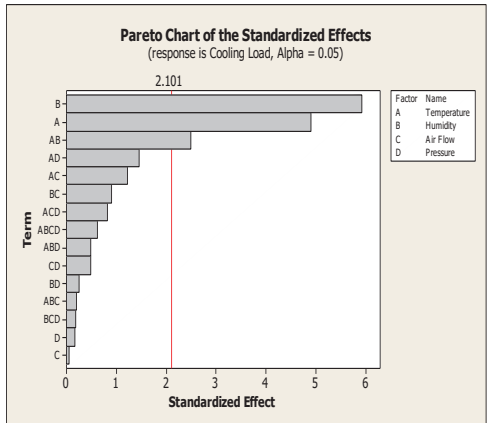

Fig. 2. Pareto chart

\subsection{First order regression model}

Regression model is a formula used to determine the predicted results of the experiment based on the significant factors of the experiment (Equation 1). Based on this experiment, the significant factors are main effect of Temperature (A), Humidity (B) and AB Interaction. In order to generate the regression model the constant coefficient value and all significant 
coefficient values should be considered. Table 4 shows the coefficients to develop the regression model.

$Y=B_{0}+B_{1} x_{1}+B_{2} x_{2}+B_{12} x_{1} x_{2}+\varepsilon$

$\mathrm{Y}=226974+18315(\mathrm{~A})+22111(\mathrm{~B})+9285(\mathrm{AB})$

Table 4. Estimated effects and coefficients for cooling load

\begin{tabular}{|c|c|c|c|c|c|}
\hline Term & \multirow{2}{*}{ Effect } & Coefficient & $\begin{array}{c}\text { SE } \\
\text { Coefficient }\end{array}$ & T & P value \\
\cline { 4 - 5 } & & 226947 & 3735 & 60.76 & 0.00 \\
\hline Constant & 36631 & 18315 & 3735 & 4.90 & 0.00 \\
\hline Temperature (A) & 44221 & 22111 & 3735 & 5.92 & 0.00 \\
\hline Humidity (B) & 18570 & 9285 & 3735 & 2.49 & 0.023 \\
\hline $\begin{array}{c}\text { Temperature * Humidity } \\
\text { (AB) }\end{array}$ & & & & \\
\hline
\end{tabular}

In order to find the optimum setting of cooling load, sensitivity analysis is used by running and comparing different scenarios. Fig. 3 (a) shows that minimum cooling load and maximum desirability will be achieved when temperature and humidity placed on low level and two other factors placed on high level. In addition, Fig 3(b) claimed that if all the factors place on center points, the maximum desirability will be $25 \%$. The minimum desirability will be achieved when all the factors place on high level (Fig 3 (c)).

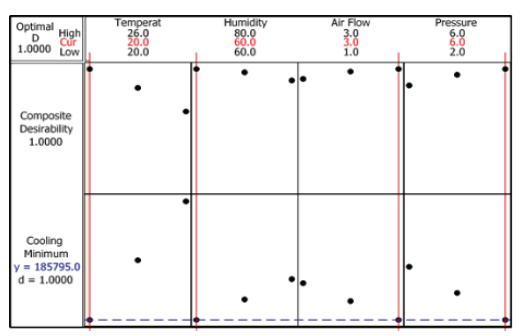

(a)

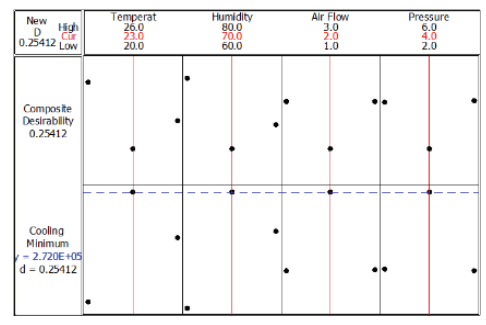

(b)

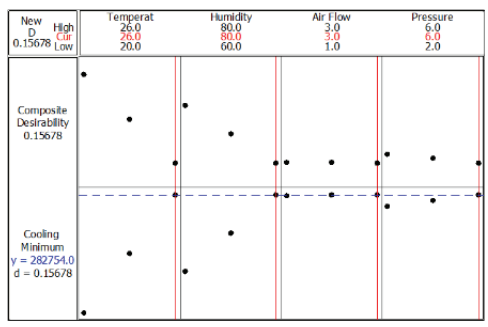

(c)

Fig. 3. Sensitivity Analysis for optimum setting

\section{Conclusion}

Energy efficient of building depends of some parameters such as climatic condition, location and physical material of buildings. In this paper, a model for assessing the effect of four climatic parameters which were temperature, humidity, airflow and pressure on cooling loads in residential tropical buildings was introduced. The design of experiments (DOE) was applied for evaluating the effect of factors on the energy saving and cooling load by running the simulation experiment. Finally, a sensitivity analysis is done to find the optimum setting 
of selected climate parameters in order minimize the cooling load. Final result claimed that maximum desirability of energy saving will be obtained when temperature and humidity is equal to $\mathrm{A}=20$ Celsius degree and $\mathrm{B}=60 \%$ respectively. In addition, the other two insignificant factors, airflow and pressure should be placed at the high level which are equal to $\mathrm{C}=3$ cubic Meters per hour and $\mathrm{D}=6$ Pascal respectively.

We gratefully acknowledge the support provided by Universiti Teknologi PETRONAS and Ministry of Higher Education Malaysia (MOHE) of Malaysia for this work under Fundamental Research Grant Scheme (FRGS), cost center: 0153AB-k88.

\section{References}

[1] S. Zahraee, M. K. Assadi, and R. Saidur, "Application of artificial intelligence methods for hybrid energy system optimization," Renewable and Sustainable Energy Reviews, vol. 66, pp. 617-630, (2016).

[2] H. Abdul-Rahman, C. Wang, and M. Y. Kho, "Potentials for sustainable improvement in building energy efficiency: Case studies in tropical zone," International Journal of Physical Sciences, vol. 6, pp. 325-339, (2011).

[3] A. N. Sadeghifam, S. M. Zahraee, M. M. Meynagh, and I. Kiani, "Combined use of design of experiment and dynamic building simulation in assessment of energy efficiency in tropical residential buildings," Energy and Buildings, vol. 86, pp. 525533, (2015).

[4] I. Iqbal and M. S. Al-Homoud, "Parametric analysis of alternative energy conservation measures in an office building in hot and humid climate," Building and environment, vol. 42, pp. 2166-2177, (2007).

[5] N. Wong and S. Li, "A study of the effectiveness of passive climate control in naturally ventilated residential buildings in Singapore," Building and Environment, vol. 42, pp. 1395-1405, (2007).

[6] M. S. Al-Homoud, A. A. Abdou, and I. M. Budaiwi, "Assessment of monitored energy use and thermal comfort conditions in mosques in hot-humid climates," Energy and Buildings, vol. 41, pp. 607-614, (2009).

[7] S. M. Zahraee, H. Milad, M. Y. Noordin, M. R. Jafri, and Z. Farhad, "Combined use of design of experiment and computer simulation for resources level determination in concrete pouring process," Jurnal Teknologi (Sciences and Engineering), vol. 64, pp. 43-49, (2013).

[8] S. M. Zahraee, G. Rezaei, A. Shahpanah, A. Chegeni, and J. M. Rohani, "Performance Improvement of Concrete Pouring Process Based Resource Utilization Using Taguchi Method and Computer Simulation," Jurnal Teknologi, vol. 69, pp. 17-24, (2014).

[9] S. M. Zahraee, M. Hatami, A. A. Bavafa, K. Ghafourian, and J. M. Rohani, Application of statistical taguchi method to optimize main elements in the residential buildings in Malaysia based energy consumption vol. 606, (2014).

[10] S. M. Zahraee, A. Khademi, S. Khademi, A. Abdullah, and H. Ganjbakhsh, "Application of design experiments to evaluate the effectiveness of climate factors on energy saving in green residential buildings," Jurnal Teknologi (Sciences and Engineering), vol. 69, pp. 107-111, (2014).

[11] D. Montgomery, "Basic experiment design for process improvement statistical quality control," ed: John Wiley and Sons, Inc., USA, (2009). 